\title{
Ensino dos esportes coletivos: as fontes de crenças pedagógicas de universitários em Educação Física
}

Ana Flávia Backes ${ }^{\mathrm{a}}{ }^{\oplus}$, Leonardo Ristow ${ }^{\mathrm{b}}$, Vinicius Zeilmann Brasil ${ }^{\mathrm{a}}$, Rodolfo Silva da Rosa ${ }^{\circledR}$, Jéssica Dias Cardoso ${ }^{\mathrm{b}}$, Valmor Ramos ${ }^{\mathrm{b}}{ }^{\circledR}$

\author{
Palavras Chave: \\ Ensino; \\ Esporte; \\ Crenças; \\ Formação inicial.
}

\begin{abstract}
RESUMO
O objetivo do estudo foi analisar as fontes de crenças sobre as estratégias de ensino dos esportes coletivos de universitários do curso de Licenciatura em Educação Física de uma universidade pública do sul do Brasil. Adotaram-se procedimentos de estudo qualitativo em que participaram 4 universitários. Os dados foram obtidos por meio de observação sistemática, seguido de entrevistas com estimulação de memória e analisados através da Análise de Conteúdo. Os resultados indicaram que as fontes de crenças estavam relacionadas as experiências de prática motora, os feedbacks e as observações de professores. Conclui-se que as crenças dos universitários se desenvolveram por experiências ao longo da vida, envolvendo diversos contextos e situações de aprendizagem.
\end{abstract}

\section{Keywords:}

Teaching;

Sport;

Beliefs;

Initial formation.

Palavras Chave:

Enseñanza;

Deporte;

Creencias;

Formación inicial.

\begin{abstract}
The aim of this study was to analyze the sources of beliefs about the teaching strategies of collective sports of undergraduate students in Physical Education at a public university in southern Brazil. Qualitative research procedures were adopted with 4 undergraduate students. The data were obtained through systematic observation, followed interviews with memory stimulation and analyzed through Content Analysis. The results indicated that the sources of beliefs were related to the experiences of motor practice, the feedbacks and the observations of teachers. It is concluded that the beliefs of the undergraduates were developed through lifelong experiences, involving different contexts and learning situations.
\end{abstract}

\section{RESUMEN}

El objetivo del estudio fue analizar las fuentes de creencias para la enseñanza del deporte colectivo de estudiantes de Educación Física en una universidad pública del sur de Brasil. Se ha realizado procedimientos de estudio cualitativo en el que han participado 4 estudiantes. Los datos fueron obtenidos mediante observación sistemática seguido de entrevistas con estimulación de la memoria y analizados por medio del análisis de contenido. Los resultados indicaron que las fuentes de las creencias estaban relacionadas con las experiencias de la práctica motora, los feedbacks y las observaciones de los maestros. Se concluye que las creencias de los estudiantes se desarrollaron a través de experiencias de toda la vida, involucrando diferentes contextos y situaciones de aprendizaje.

\footnotetext{
a Universidade Federal de Santa Catarina - UFSC, Centro de Desportos, Programa de Pós-Graduação em Educação Física, Florianópolis, SC, Brasil.

b Universidade do Estado de Santa Catarina - UDESC, Centro de Ciências da Saúde e do Esporte, Programa de Pós-Graduação em Ciências do Movimento Humano, Florianópolis, SC, Brasil.
} 


\section{INTRODUÇÃO}

A influência das experiências do professor na sua forma de ensinar o esporte está amplamente documentada na agenda investigativa internacional (Feu et al., 2019; Moy et al., 2016) e brasileira (Ramos et al., 2018; Souza et al., 2018). Diversos estudos (Feu et al., 2019; Moy et al., 2016; Souza et al., 2018) evidenciam que as experiências esportivas dão base para 0 ensino da Educação Física e dos esportes. No âmbito educacional, uma das perspectivas utilizadas para a análise da influência das experiências na construção do conhecimento pedagógico do professor tem sido o conceito de crenças (Pajares, 1992; Skott, 2015).

As crenças dos professores compreendem representações mentais associadas a verdades subjetivas, as quais são balizadoras de seus pensamentos e ações sobre o ensino (Pajares, 1992). Devido ao seu caráter pessoal, elas se tornam relativamente resistentes, sobretudo porque são adquiridas a partir de experiências significativas, em contextos sociais diversos (Pajares, 1992). Portanto, as crenças conferem particularidades ao modo como cada professor ensina, tendo como um dos componentes constituintes as crenças sobre as estratégias de ensino. Esta categoria designa o conjunto de crenças sobre os procedimentos, os métodos, as tarefas de aprendizagem, que o professor acredita que devem ser priorizados (Navarro, 2012).

Para os professores em formação, as crenças atuam como filtros que condicionam as interpretações sobre novas experiências de aprendizagem, selecionando o que acreditam ser importante e desconsiderando aquilo não é relevante para a sua formação e atuação (Skott, 2015). Na Educação Física, estudos revelam que os universitários ao ingressarem no curso de formação profissional, já vivenciaram inúmeras horas de prática esportiva em contexto escolar, familiar e esportivo (Ramos et al., 2018; Souza et al., 2018). Essas experiências acumuladas ao longo da vida desenvolvem crenças sobre o ensino dos esportes, de modo que no início do curso de graduação eles já possuem uma ideia prévia sobre as estratégias que devem ser adotadas (Moy et al., 2016; Souza et al., 2018).

Estudos com foco nas crenças de universitários sobre o ensino têm analisado as suas perspectivas sobre objetivos de aprendizagem (Sofo et al., 2012) os conteúdos e estratégias de ensino (Ní Chróinín e O'Sullivan, 2016; Syrmpas et al., 2017). Por outro lado, verifica-se uma lacuna de evidências sobre as fontes de crenças pedagógicas para o ensino do esporte (Souza et al., 2018). De fato, uma compreensão detalhada sobre o processo pelo qual os universitários constroem suas crenças para o ensino dos esportes pode favorecer o desenvolvimento da identidade pedagógica que definem as suas escolhas durante o curso de graduação e influenciam a sua prática docente (Hordvik et al., 2019; Luguetti et al., 2019; Souza et al., 2018).

Neste sentido, os professores formadores devem conhecer as fontes de crenças dos universitários, a fim de identificar o seu nível de solidez, considerando que as experiências afetivamente significativas possuem potencial de desenvolver crenças mais resistentes ao longo do tempo (Tsangaridou, 2006). Desta forma, é possível propor um ambiente de formação compatível com as experiências prévias dos universitários, impulsionando o engajamento em sua própria formação, além de possibilitar a modificação de crenças que não são úteis à formação pedagógica para o ensino dos esportes. Assim, o objetivo do estudo foi analisar as fontes de crenças sobre as estratégias de ensino dos esportes coletivos de universitários do curso de Licenciatura em Educação Física de uma universidade pública do sul do Brasil.

\section{MÉTODO}

Realizou-se um estudo qualitativo, descritivo e interpretativo (Denzin e Lincoln, 2006).

\section{Participantes}

Participaram do estudo quatro universitários do último ano do curso de Licenciatura em Educação Física de uma universidade pública do sul do Brasil, selecionados intencionalmente, mediante aos critérios: a) estar regularmente matriculados na disciplina de estágio supervisionado no Ensino Fundamental; b) apresentar como tema os esportes coletivos; c) estar disposto a participar do estudo. Os participantes eram do sexo masculino, com idade entre 22 e 36 anos e apresentavam experiência esportiva prévia com esporte. Das 504 horas totais de estágio curricular obrigatório, distribuídas em dois semestres na Universidade investigada, no momento da pesquisa, todos os universitários já haviam completado 252 horas referente ao seu primeiro estágio e encontravam-se ao final de seu último estágio, que possuía igualmente a carga horária de 252 horas.

\section{Instrumentos e Procedimentos de Coleta de Dados}

Para a obtenção dos dados, utilizou-se a combinação das técnicas de observação sistemática e entrevista, com procedimento de estimulação de memória (Clark e Perterson, 1986). Uma matriz analítica foi utilizada, sendo constituída por temas a respeito das fontes de crenças sobre as estratégias de instrução, tarefa de 
aprendizagem, gestão dos recursos e relações sociais para o ensino dos esportes. Foram observadas três aulas sobre esportes coletivos de cada universitário durante o estágio supervisionado, conforme o interesse dos participantes (U1=Futsal; U2=Rugby; U3=Rugby; U4=Futsal). 0 registro das observações ocorreu por meio de uma câmera, posicionada na diagonal do espaço em que ocorreram as aulas, a uma distância que possibilitou a visualização absoluta do contexto de ensino. As intervenções verbais foram captadas por um gravador e um microfone de lapela acoplado na vestimenta dos participantes. O tempo de duração de cada aula foi de aproximadamente 45 minutos.

Posteriormente, as aulas foram reproduzidas e os universitários, individualmente, foram estimulados a descrever as experiências, os contextos e situações significativas para a construção de suas crenças a respeito das estratégias adotadas nas observações. 0 procedimento foi conduzido pelo mesmo pesquisador, em local de conveniência para os universitários. As aulas foram exibidas em três computadores com o programa de reprodução de vídeo e áudio Windows Media Player. O tempo médio da estimulação de memória para cada participante foi de $1 \mathrm{~h} 30 \mathrm{~min}$. As informações foram transcritas com os softwares Express Scribe (áudio) e Microsoft Word (texto).

\section{Análise dos Dados}

$\mathrm{Na}$ análise dos dados empregaram-se a Análise de Conteúdo (Bardin, 2016) com auxílio do software NVivo 9. Adotaram-se categorias a priori (estratégias: instrução, tarefas de aprendizagem, gestão dos recursos de ensino e relações sociais) e a posteriori (contextos: experiências antes da formação inicial e experiências durante a formação inicial; situações: prática motora, observação e feedbacks). A análise compreendeu as fases: 1) Pré-análise, relativo à seleção e organização das informações contidas nas transcrições; 2) Exploração do material, referente à classificação do conteúdo em função das categorias de análise; c) Tratamento dos resultados, relacionado à ocorrência das unidades de significado para cada tema investigado.

Realizaram-se procedimentos de checagem interpesquisador, que consistiu na apreciação dos dados por outro pesquisador, não encontrando discrepância entre informações (Maxwell, 2012). O estudo foi aprovado pelo Comitê de Ética em Pesquisa com Seres Humanos de uma universidade pública (2.083.301). Todos os participantes assinaram o Termo de Consentimento Livre Esclarecido. Para preservar o seu anonimato, os universitários foram identificados através de letras e números (U1, U2, U3 e U4).

\section{RESULTADOS}

Os resultados estão apresentados por meio de um mapa conceitual, elaborado com a ferramenta CmapTools. Na parte central, constam as categorias relativas às estratégias de ensino. Nas extremidades encontram-se as fontes de crenças dos universitários para o ensino dos esportes, antes e durante a formação inicial. As frequências para cada fonte estão representadas através de números e linhas de ligação. As linhas tracejadas referem-se a menor frequência e as linhas em negrito a maior frequência.

\section{Experiências anteriores à formação inicial}

As experiências anteriores à formação inicial compreenderam os contextos das aulas de Educação Física escolar e a iniciação e treinamento esportivo. Referente às estratégias de instrução, verificou-se que os feedbacks dos professores e/ou treinadores (U1, U2, U3, U4) contribuíram no modo como todos os universitários instruem seus alunos, sobretudo, durante a execução das tarefas de aprendizagem:

"O professor de Educação Física fazia algo parecido com isso, de sempre que se realizava alguma atividade, ele ficava sempre falando: - Coloca a bola aqui! Vai lá!... Ele falava várias coisas que falo" (U2).

"Eu chegava na borda da piscina e o treinador dizia: - Nossa! Tu melhorou bastante, teu movimento está bem melhor" (U3).

As experiências de prática motora (U1, U4), nas aulas de Educação Física escolar, proporcionaram aos universitários a construção de crenças sobre o uso de explicações verbais para apresentar o novo conteúdo, conforme U4:

"Em toda a minha trajetória escolar foi assim. Enquanto fazia as aulas, se não foram todos, foram quase todos professores, só explicavam a atividade e não demonstravam".

Referente às observações dos professores e/ou treinadores (U1, U4), destaca-se o modo como U1 aprendeu observando o treinador de futsal, sobre o uso da demonstração para apresentar um conteúdo de maior complexidade aos alunos:

"No caso da demonstração, foi em treinos de futsal. Às vezes, como era uma jogada ensaiada, eu via que o treinador pedia para todo mundo ver como é que era, para a gente assimilar. Eu vi que como era mais complexo, era mais importante fazer assim"(U1). 
Figura 1 - Mapa conceitual das fontes de crenças sobre as estratégias de ensino dos esportes coletivos.

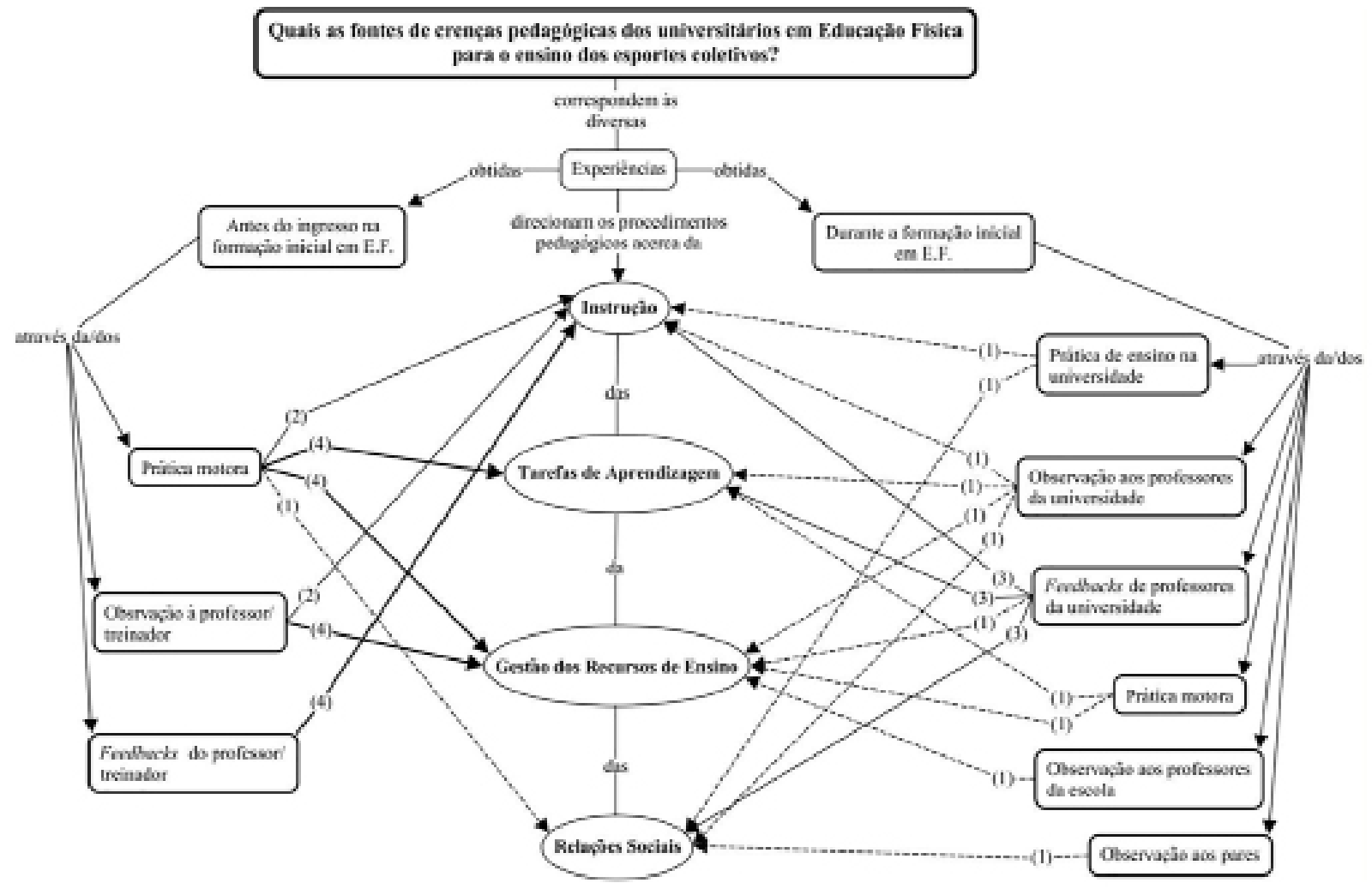

Fonte: Os autores (2019).

Quanto às tarefas de aprendizagem, apenas as situações de prática motora (U1, U2, U3, U4), foram consensualmente indicadas por todos os universitários. Assim, destacam-se como os universitários aprenderam a utilizar tarefas analíticas no ensino dos esportes coletivos:

"Isso eu aprendi no futebol, porque a gente fazia bem isso que eu estava fazendo. Fragmentava os fundamentos, depois você juntava tudo e fazia um coletivo para ver na prática quais efeitos tinha surtido" (U3).

"Eu acho que foi o que deu certo pra mim e eu levei pra eles. Foi eficiente pra mim. Como eu fui treinando, eu senti minha evolução e eu achei que era uma forma que podia ser eficiente pra eles também" (U1).

Sobre a gestão dos recursos de ensino, todos os universitários enfatizaram a contribuição das situações de prática motora (U1, U2, U3, U4), no contexto escolar para a aprendizagem da gestão dos alunos e dos materiais:

"Isso eu aprendi com minhas experiências como aluno na escola, as aulas práticas eram realizadas geralmente em grupo, então aprendi na experiência mesmo" (U4).
"Foi algo que eu aprendi desde as primeiras aulas de Educação Física que eu tive. A gente foi muito regrado quanto a isso. De o material estar separado num lugar e não era para a gente mexer, só se a gente for autorizado" (U3).

Com referência à observação de professores e/ou treinadores (U1, U2, U3, U4) todos os universitários indicaram ter aprendido a organizar os alunos e os materiais em sua rotina, a partir de observação da gestão adotada por seus professores de Educação Física escolar:

"Eu via que nas minhas aulas de Educação Física eram assim também. A professora vinha com o saco de materiais, explicava a atividade e depois, ela dava o material" (U1).

"Observando o meu professor da escola, ele fazia basicamente isso também. Posicionava os alunos em fila, dava um comando e o pessoal ia lá e arremessava" (U2).

Para as relações sociais, apenas o U1 citou que as experiências de prática motora enquanto aluno, contribuíram para o entendimento do papel do professor nas tomadas de decisão: 
"Não era a gente que decidia, ela chegava e dizia: - hoje é futebol. Tanto que quando não era, ela nem levava a bola de futebol... mas era ela quem decidia".

\section{Experiências durante a formação inicial em Educação Física}

As experiências durante a formação inicial foram provenientes dos contextos dos estágios supervisionados e das disciplinas curriculares. Relativo às estratégias de instrução, os universitários indicaram que as situações de aprendizagem decorreram predominantemente dosfeedbacks dos professores das disciplinas curriculares e/ou do estágio supervisionado (U1, U2, U4) logo após as práticas de ensino no estágio e da prática motora nas disciplinas do curso:

"Foi nas duas ou três primeiras aulas do estágio que a gente ministrou e o professor deu um feedback uma manhã inteira de como poder melhorar, o que poderia ser feito de outra forma. $E$ eu aprendi a fazer desse jeito os questionamentos com os alunos" (U4).

"Na aula de basquete, o professor falava isso. Em todas as aulas, principalmente nas aulas de arremesso, falava algo parecido: - Posiciona o corpo! Flexiona o joelho! Faz o movimento da mão, cotovelo e punho!" (U2).

As experiências de prática de ensino no estágio supervisionado contribuíram para U2 estimular o engajamento dos alunos nas tarefas de aprendizagem, através de feedbacks positivos:

"Eles são assim: eles fazem uma coisa, vê que se ele (o colega) fizer errado, o outro começa a rir e ele já quer sair da aula. Então percebendo isso, eu pensei comigo: - vou dar uma estimulada neles. Só o fato de ele realizar, eu vou dizer: - Boa! Legal!".

As situações de observação da instrução de professores das disciplinas curriculares, também auxiliaram U2 a combinar estratégias instrucionais em sua rotina de ensino:

"Nas aulas aqui na universidade, na aula de atletismo. Eu observei que o professor fazia algo parecido, explicava e depois ele mostrava o movimento, a largada principalmente".

Relativo às tarefas de aprendizagem, a maioria dos universitários indicaram que os feedbacks recebidos de professores das disciplinas curriculares e/ou do estágio supervisionado (U1, U3, U4), contribuíram para o uso de jogos recreativos para ensinar o esporte:
"Eu sempre conversava com a professora supervisora, porque ela tinha mais experiência. Ela deu a ideia de tentar ligar uma brincadeira no começo que fosse voltada para o que a gente quisesse" (U1).

"Aqui no curso. Eles sempre batem nessa tecla do jogo. O esporte não precisa ser só aquilo, tem outras formas de ensinar aquele mesmo conteúdo. Essa professora falava isso na disciplina de lazer" (U3).

A observação das tarefas de aprendizagem adotadas pelos professores nas disciplinas curso desenvolveu em U2, crenças sobre a aplicação do jogo formal ao final das aulas:

"Nas aulas dos professores, principalmente nas aulas de handebol, eu via que a professora utilizava muito. Sempre no fim dessas atividades, ela fazia um jogo formal para poder relembrar aquilo que tinha sido aprendido anteriormente".

As experiências de prática motora nas tarefas de aprendizagem propostas por professores das disciplinas do curso, também contribuíram para U2 usar jogos condicionados em suas aulas:

"Foi fazendo as aulas práticas aqui na universidade. Na aula de futebol de campo, o professor fez atividades que relembravam isso, ataque contra defesa".

Para a gestão dos recursos de ensino, a observação de professores das disciplinas curriculares e/ou do estágio supervisionado, assim como os professores regentes das escolas (U2, U3) foi a fonte mais citada pelos universitários. Assim, destaca-se como U3 aprendeu a negociar a gestão de materiais com os alunos, observando o professor regente da escola:

"Quando a gente estava acompanhando as aulas do professor, ele fazia o que eles estavam a fim de fazer. É mais fácil tu agradar os alunos e fazer com que eles participem".

As experiências de prática motora nas disciplinas curriculares contribuíram para a aprendizagem de U2 sobre a gestão dos alunos:

"Isso aquié tudo aqui da universidade, vivenciando aulas, participando de aulas. Específico a aula de vôlei, o professor fazia bastante isso".

Para as relações sociais, a maioria dos universitários enfatizaram os feedbacks e orientações de professores das disciplinas curriculares e/ ou do estágio supervisionado (U2, U3, U4). Essas 
experiências auxiliaram os universitários a identificar o papel do professor na condução das relações sociais com os alunos:

"Nesse campo de estágio, a professora supervisora também falava muito disso, a postura do professor. Que é importante ter essa postura. Ela até falava isso pra mim, que eu tinha uma postura boa frente aos alunos"(U2).

"Aqui no curso. Aprendi com o professor supervisor, nas aulas teóricas de estágio, em que nós fazíamos leitura de texto, ele trazia e relacionava com as aulas que a gente iria ministrar"(U4).

As experiências de prática de ensino no estágio foram importantes para U1 adotar uma conduta mais firme perante aos alunos, em relação às tomadas de decisão no processo de ensino e aprendizagem:

"Pela experiência mesmo. Todos os dias, todas as aulas, eles pediam para ser futebol. Eu tinha que falar: - não, hoje vai ser isso! Até eles entenderem e parar de pedir. Eles entenderam e aceitaram".

As situações de aprendizagem pela observação $(\mathrm{U} 3, \mathrm{U} 4)$ docomportamentodeprofessores das disciplinas curriculares do curso de graduação e dos pares, parecem ter influenciado as crenças dos universitários sobre como compartilhar responsabilidades e estabelecer relações mais consensuais com seus alunos:

"Foi vendo a forma como ele conduzia a aula. Ele perguntou o que a gente achava de discutir sobre tal assunto, se achava que era relevante discutir aquilo naquela aula. E a turma entrou num consenso de que valeria a pena" (U3).

"Teve a participação de estagiários antigos que mostraram como eles desenvolviam a aula. Então foi nesse sentido que a gente aprendeu a dividir a responsabilidade da aula com os alunos" (U4).

\section{DISCUSSÃO}

Os resultados apontaram a valorização de diferentes experiências obtidas antes e durante o curso de formação profissional, destacadamente, a prática motora, as observações e os feedbacks recebidos. De modo semelhante, estudos com universitários em Educação Física evidenciam o desenvolvimento de crenças sobre o ensino a partir de variadas situações e contextos de aprendizagem (Ramos et al., 2018; Tsangaridou, 2008).
Embora diversas experiências tenham sido mencionadas, os resultados evidenciaram que as situações que envolviam a prática motora foram recorrentes nas declarações de todos os universitários investigados, sobretudo, antes do ingresso na formação inicial. Este tipo de experiência pode ser denominado de experiência direta, sendo consideradas centrais para a construção das crenças pedagógicas, na medida em que proporcionam evidências concretas sobre as próprias capacidades de ação para alcançar o êxito em tarefas específicas (Navarro, 2012).

Os universitários mencionaram que aprenderam a realizar todas as estratégias de ensino, por meio das situações de prática motora nas aulas de Educação Física escolar e de iniciação esportiva. A prática motora pode ser interpretada como um tipo de "experiência pessoal ativa" (personal enactive experiences) (Buehl e Fives, 2009), contemplando o aspecto sensorial da aprendizagem, onde a ação é um elemento constitutivo da cognição do aluno. Nesta perspectiva, as experiências sensório-motoras ficam registradas na memória, influenciando na forma como os indivíduos realizam determinados comportamentos.

Em parte, isso acontece porque a prática motora ocorre em contextos autênticos de aprendizagem, associadas à diversão, a interação social com colegas e/ou professor, ao sentimento de desafio individual, de competência na aprendizagem de habilidades motoras e ao engajamento em tarefas de aprendizagem que são considerados pessoalmente relevantes para suas vidas. Portanto, essas experiências são consideradas significativas, na medida em que os sujeitos incorporam valores, símbolos ou emoções, atribuindo significado pessoal à prática motora (Ní Chróinín et al., 2018).

Estudos mostram que em suas primeiras experiências docentes, os universitários tendem a imitar ou reproduzir práticas motoras realizadas na infância, devido à familiaridade com os elementos das aulas/treinos enquanto alunos ou atletas, geralmente priorizando aspectos técnicos ou motores (Souza et al., 2018; Syrmpas et al., 2017), tarefas de aprendizagem analíticas (Feu et al., 2019; Moy et al., 2016) e gestão controlada dos recursos de ensino (Ní Chróinín et al., 2016).

Há evidências, de que a formação inicial têm apresentado impacto reduzido no processo de (re) construção de crenças para o ensino, sobretudo, devido à natureza das situações de aprendizagem no ambiente de formação, pouco compatíveis com a natureza das fontes de crenças dos universitários (Feu et al., 2019; Milistetd et al., 2018; Tsangaridou, 2006). $\mathrm{O}$ fato de os universitários deste estudo mencionarem ao final da graduação, as experiências de prática 
motora obtidas na infância, pode indicar que algumas situações de aprendizagem oferecidas durante a formação não foram suficientemente significativas para promover alterações em suas crenças, destacadamente, sobre as tarefas de aprendizagem e a gestão dos recursos no ensino.

Os feedbacks emitidos pelos professores formadores, no contexto do estágio e nas disciplinas curriculares corresponderam à principal fonte de crenças para a instrução, tarefas de aprendizagem e relações sociais no ensino dos esportes. A exposição a julgamentos verbais de pessoas consideradas referências, denominadas como persuasão social, possuem o potencial de influenciar as percepções dos indivíduos com menor experiência no ensino (Navarro, 2012). Isso ocorre porque as orientações e feedbacks são provenientes de experiências marcadas pela interação e colaboração social (interactive and collaborative experiences), em que os professores experts e mentores desempenham importante papel mediador no processo de reflexão e (re)construção de significados das experiências de ensino dos universitários (Buehl et al., 2009).

Neste estudo, as orientações e sugestões fornecidas por professores parecem ter auxiliado os universitários a refletirem sobre alguns aspectos de sua prática, particularmente, "como melhorar" ou repensar "de outra forma" o ensino, a estabelecerem "relações" entre teoria e prática, a identificarem como "fazer o movimento" em determinado esporte e, em alguns momentos, a refletir positivamente sobre os seus comportamentos durante as aulas. Neste caso, acredita-se que as orientações e feedbacks fornecidos, só fizeram sentido após uma experiência de prática, seja ela de ensino ou motora.

De modo semelhante, estudo com universitários de Educação Física mostram que os momentos de reflexão e feedbacks proferidos pelos professores durante e após as experiências de ensino dos universitários, auxiliaram na percepção de autoconfiança diante dos primeiros contatos com a docência (Laker et al., 2008) e também, para a (re)construção de crenças que promoveram melhor gestão do tempo para organização da aula, das atividades propostas, dos momentos de instrução e para a o tempo de espera (Vassiliadou et al., 2009).

Outra relevante fonte de crenças para os universitários foi a observação, sendo recorrente, sobretudo, nas aulas de Educação Física escolar e nos treinos de escolinhas esportivas, antes do ingresso na formação inicial, assim como nas disciplinas do curso de Educação Física. O observador confere mais importância a esse tipo de experiência quando constata semelhanças com o indivíduo observado, ou quando o mesmo é considerado um "modelo" para ele (Navarro, 2012). No caso dos universitários investigados, diferentes "pessoas modelo" parecem ter contribuído para a construção de suas crenças, destacadamente, os professores da escola, assim como os professores da graduação e os pares (universitários).

Neste estudo, essas experiências contribuíram para a construção de crenças sobre a gestão. Resultados similares foram encontrados em estudos na Educação Física (Hand, 2014; Jenkins, 2014), em que ao assistirem, sistematicamente, as aulas de professores experientes, os universitários direcionaram sua observação, para comportamentos instrucionais, a gestão de materiais utilizados e também, no modo como os professores se relacionavam e organizavam os alunos em aula. De fato, a imitação de "modelos" tem sido evidenciada em investigações realizadas no âmbito da aprendizagem profissional de professores de Educação Física (Jenkins, 2014; Tsangaridou, 2006).

Constatou-se um consenso em relação às fontes de crenças mencionadas pelos universitários (prática motora, feedback e observação), antes e durante a formação inicial, para todas as dimensão de ensino. Por outro lado, referente às tarefas de aprendizagem verificou-se que os universitários mencionaram a aprendizagem de perspectivas analíticas para o ensino dos esportes em suas experiências de prática motora antes da formação inicial, sendo que os feedbacks dos professores formadores em situações da formação inicial foram indicados como fontes de crenças para a utilização de jogos recreativos para o ensino do esporte. Essas evidências parecem revelar que as crenças possuem uma natureza integrativa das experiências obtidas ao longo da vida, sendo armazenadas conforme uma organização hierárquica pessoal de cada indivíduo dos significados e valores que constituem suas crenças (Pajares, 1992). Ainda, as dissonâncias verificadas entre as experiências prévias e os novos conhecimentos adquiridos durante a formação inicial, também retratam a pouca efetividade das oportunidades formativas nos cursos de formação inicial e a complexidade de alcançar níveis mais profundos de mudança conceitual nas crenças dos universitários (Syrmpas et al.,2018).

Nesse sentido, estudos com universitários de Educação Física apontam a necessidade de oportunidades formativas em que os futuros profissionais reflitam sobre suas crenças e conhecimentos para a intervenção pedagógica (Feu et al., 2016; Tsangaridou e Polemitou, 2015). A utilização da técnica de mapas conceituais (Eppler, 2006; Novak e Cañas, 2010) compreende uma importante 
possibilidade para os universitários revelarem conhecimentos, crenças e significados pessoais à prática esportiva e ao ensino dos esportes. Estes elementos podem servir como referência para o professor formador introduzir novos conhecimentos, para os próprios universitários refletirem individualmente sobre suas perspectivas pessoais e também, para confrontarem suas crenças com as crenças de seus colegas de classe (Novak e Cañas, 2010).

Outras estratégias utilizadas para o engajamento dos universitários em um processo reflexivo sobre suas crenças para o ensino dos esportes têm sido as discussões reflexivas após observações orientadas por fichas de professores mais experientes (Coulter et al., 2019), o preenchimento de diário reflexivo após as experiências de prática docente (Ní Chróinín et al., 2018), o autoestudo com reflexões estimuladas por um amigo crítico após a prática de ensino (Fletcher et al., 2018), o autoestudo colaborativo, com reflexões estimuladas por um amigo crítico e um amigo meta-crítico (Luguetti et al., 2019) e reflexões em grupos com base em estudos de caso (Hemphill et al., 2015). Em vista de alcançar a efetividade destas estratégias é fundamental que o professor formador tenha clareza sobre os diferentes tipos de reflexão (reflexão na ação, reflexão sobre a ação e reflexão sobre a reflexão na ação), assim como o potencial formativo de cada um deles (Hatton e Smith, 1995; Shon, 2000), fazendo com que os acadêmicos reformulem suas crenças mais estáveis, as quais estão vinculadas a suas experiências mais marcantes (infância) (Tsangaridou, 2006).

Portanto, para os cursos de graduação em Educação Física e professores formadores, é importante considerar que os universitários ao ingressarem no Ensino Superior, possuem um grande número de experiências de prática motora em esportes, como também, representações da prática pedagógica de seus professores e/ou treinadores obtidas por meio de observações e feedbacks recebidos. Essas experiências desenvolvem crenças, atuando como um filtro na aquisição de novos conhecimentos. Considerando que a aprendizagem profissional ocorre ao longo da vida, essas experiências devem ser exploradas e refletidas de forma sistematizada e contínua durante a formação inicial.

\section{CONCLUSÕES}

O estudo analisou as fontes de crenças sobre as estratégias de ensino dos esportes coletivos de universitários do curso de Licenciatura em Educação Física. As fontes de crenças dos universitários constituíram-se de diferentes experiências ao longo da vida, envolvendo diversos contextos e situações, antes e durante a formação inicial, com destaque para as situações de prática motora, feedbacks e observações. As práticas motoras na infância compreenderam experiências significativas, pois ao final do curso, os universitários ainda se remeteram a elas para justificarem suas crenças pedagógicas, sobretudo, para as tarefas de aprendizagem e a gestão dos recursos de ensino. Os feedbacks dos professores universitários durante a graduação contribuíram particularmente para a adoção de estratégias de instrução e relações sociais, assim como as observações dos professores e treinadores na infância e dos professores universitários na graduação, também foram importantes para a gestão dos recursos de ensino.

As limitações do estudo estão relacionadas à utilização da estimulação de memória somente ao final do curso de graduação, de modo que os universitários podem ter se recordado de memórias recentes, e não mencionado outras importantes experiências de vida. Além disso, não foi considerada a possível influência das características e/ou especificidades inerentes ao ensino dos diferentes esportes coletivos adotados pelos universitários, na análise das fontes de suas crenças. Ainda, analisaram-se apenas as crenças sobre as estratégias de ensino dos esportes e, portanto, outras categorias de crenças como a aprendizagem dos alunos, conteúdos, avaliação e o papel do professor podem ser exploradas em estudos futuros. Assim, sugere-se a realização de estudos longitudinais para analisar como as crenças se desenvolvem ao longo da formação inicial identificando as situações que contribuem para a construção e/ou modificação de crenças sobre o ensino dos esportes. $O$ uso de pesquisa-ação em disciplinas específicas do curso, com objetivo de verificar como determinado ambiente de aprendizagem profissional (situações e contextos) podem levar os universitários a desenvolverem crenças coadunadas às abordagens atuais de ensino dos esportes também pode contribuir para a área de investigação.

\section{REFERÊNCIAS}

Bardin L. Análise de conteúdo. São Paulo: Edições 70; 2016.

Buehl MM, Fives $\mathrm{H}$. Exploring teachers' beliefs about teaching knowledge: where does it come from? does it change? J Exp Educ 2009;77(4):367-408. DOI:10.3200/JEXE.77.4.367-408

Clark C, Perterson PL. Teacher's thought process. In: Wittrock $M$, editor. Handbook of research on teaching. New York: Macmillan; 1986. p. 255-96.

Coulter M, Kealey F, Langan SL, McGarvey J, Padden S. Seeing is believing: primary generalist pre-service teachers' observations of physical education lessons in Ireland and Switzerland. Eur Phys Educ Rev 2019;25(4):1-20. DOI:10.1177/1356336×19839412 
Denzin NK, Lincoln SY. O planejamento da pesquisa qualitativa: teorias e abordagens. Porto Alegre: Artmed; 2006.

Eppler MJ. A comparison between concept maps, mind maps, conceptual diagrams, and visual metaphors as complementary tools for knowledge construction and sharing. Information Visualization 2006;5:202-210. DOI:10.1057/palgrave.ivs.9500131

Feu S, Vizuete M, Cruz-Sánchez E, Gragera-Alonso A. Importancia de las experiencias previas em la vocación y elección de la titulación de maestro com mención em educación física. Movimento 2016;22(3):929-942. DOI:10.22456/1982-8918.59282

Feu S, García-Rubio J, Gamero MG, Ibáñez SJ. Task planning for sports learning by physical education teachers in the preservice phase. PLoS One 2019;14(3):1-18. DOI:10.1371/ journal.pone. 0212833

Fletcher T, Ní Chróinín D, Price C, Francis N. Teacher educators' enactment of pedagogies that prioritise learning about meaningful physical education. Curriculum Stu Health Phys Educ 2018;9(1):76-89. DOI:10.1080/18377122.2018.1425125

Hand KE. Building confident teachers: preservice Physical Education teachers' efficacy beliefs. J Case Stu Educ 2014;6:1-9.

Hatton N, Smith, D. Reflection in teacher education: towards definition and implementation. Teach Teach Educ 1995;11(1):33-49. DOI:10.1016/0742-051X(94)00012-U

Hemphill MA, Richards KA, Gaudreault KL, Templin TJ. Preservice teacher perspectives of case-based learning in physical education teacher education. Eur Phys Educ Rev 2015;21(4):432-50. DOI:10.1177/1356336x15579402

Hordvik M, MacPhail A, Ronglan LT. Learning to teach sport education: investigating a pre-service teacher's knowledge development. Sport Educ Soc 2019;24(1):51-65. DOI:10.10 80/13573322.2017.1322948

Jenkins JM. Pre-service teachers' observations of experienced teachers. Phys Educ 2014;71(2):303-19.

Laker A, Laker JC, Lea S. Sources of support for pre-service teachers during school experience. Mentoring and Tutoring 2008;16(2):125-40. DOI:10.1080/13611260801916234

Luguetti C, Aranda R, Nuñez Enriquez O, Oliver KL. Developing teachers' pedagogical identities through a community of practice: learning to sustain the use of a studentcentered inquiry as curriculum approach. Sport Educ Soc 2019;24(8):855-66. DOI:10.1080/13573322.2018.1476336

Maxwell JA. Qualitative research design: an interactive approach. Thousand Oaks: Sage publications; 2012.

Milistetd M, Ciampolini V, Mendes MS, Cortela CC, Nascimento JV. Student-coaches perceptions about their learning activities in the university context. Rev Bras Cien Esp 2018;40(3):281-7. DOI:10.1016/j.rbce.2018.03.005

Moy B, Renshaw I, Davids K, Brymer E. Overcoming acculturation: physical education recruits' experiences of an alternative pedagogical approach to games teaching. Phys Educ Sport Peda 2016;21(4):386-406. DOI:10.1080/1 7408989.2015.1017455
Navarro LP. Autoeficacia del profesor universitario. Madrid: Narcea Ediciones; 2012.

Ní Chróinín D, Fletcher T, O’Sullivan M. Pedagogical principles of learning to teach meaningful physical education. Phys Educ Sport Peda 2018;23(2):117-33. DOI:10.1080/174089 89.2017.1342789

Ní Chróinín D, O'Sullivan M. Elementary classroom teachers' beliefs across time: learning to teach Physical Education. J Teach Phys Educ 2016;35(2):97-106. DOI:10.1123/jtpe.2015-0030

Novak JD, Cañas AJ. A teoria subjacente aos mapas conceituais e como elaborá-los e usá-los. Práx Educ 2010;5(1):9-29. DOI:10.5212/PraxEduc.v.5i1.009029

Pajares MF. Teachers' beliefs and educational research: cleaning up a messy construct. Rev Educ Res 1992;62(3):307-32. DOI:10.3102/00346543062003307

Ramos V, Souza JRd, Brasil VZ, Backes AF, Costa MdL, Kuhn F. As crenças de universitários formandos de um curso de Educação Física - bacharelado, sobre o ensino dos esportes. Motrivivência 2018;30(54):15.DOI:10.5007/21758042.2018v30n54p210

Shon D. Educando o profissional reflexivo: um novo design para o ensino e a aprendizagem. Porto Alegre: Artmed; 2000.

Skott J. The promises, problems, and prospects of research on teachers' beliefs. In: Fives H, Gill MG, editors. International handbook of research on teachers' beliefs. 2015. p. 37-54.

Sofo S, Beard DH, Slattery A, Howard S. Preservice teachers' beliefs about the curricular goals for Physical Education. Mo J Health Phys Educ Recreat Dance 2012;22:18-35

Souza JR, Ramos V, Brasil VZ, Kuhn F, Backes AF, Goda C, et al. Initial physical education students' beliefs about sport teaching. Educ Fís Cien 2018;20(3):1-12. DOI:10.24215/23142561e052

Syrmpas I, Digelidis N, Watt A, Vicars M. Physical education teachers' experiences and beliefs of production and reproduction teaching approaches. Teach Teach Educ 2017;66:184-94. DOI:10.1016/j.tate.2017.04.013

Syrmpas I, Chen S, Pasco D, Digelidis N. Greek preservice physical education teachers' mental models of production and reproduction teaching styles. Eur Phys Educ Rev 2018;25(2):544-564. DOI:10.1177/1356336X17752627

Tsangaridou N. Teachers' beliefs. In: Kirk D, Macdonald D, O'Sullivan M, editors. Handbook of Physical Education. Londres: Sage Publications; 2006. p. 486-501.

Tsangaridou N. Trainee primary teachers' beliefs and practices about physical education during student teaching. Phys Educ Sport Peda 2008;13(2):131-52. DOI:10.1080/17408980701345667

Tsangaridou N, Polemitou I. Exploring pre-service classroom teachers' reflections on teaching physical education. Eur Phys EducRev2015;21(1):66-82.DOI:10.1177/1356336×14550941

Vassiliadou O, Derri V, Galanis N, Emmanouilidou K. Training in-service physical educators to improve class time management. RICYDE 2009;5(17):33-43. DOI:10.5232/ricyde 